Article

\title{
The Perception of Overtourism from the Perspective of Different Generations
}

\author{
Adam R. Szromek ${ }^{1}\left(\mathbb{D}\right.$, Beata Hysa ${ }^{1, *(1)}$ and Aneta Karasek ${ }^{2}$ \\ 1 Department of Organization and Management, Institute of Economy and Informatics, Silesian University \\ of Technology, Akademicka 2A, 44-100 Gliwice, Poland; adam.szromek@polsl.pl \\ 2 Faculty of Economics, Maria Curie-Sklodowska University, Plac Marii Skłodowskiej-Curie 5, \\ 20-031 Lublin, Poland; aneta.karasek@umcs.pl \\ * Correspondence: beata.hysa@polsl.pl; Tel.: +48-32-277-7336
}

Received: 15 November 2019; Accepted: 11 December 2019; Published: 13 December 2019

check for updates

\begin{abstract}
The problem of overtourism, i.e., tourist congestion in visited places, and the negative impacts of tourists on the environment and residents, are increasingly noticeable with the increase in popularity of tourism. In addition, human impact on the environment is often negative in relation to the assumptions of the concept of sustainable development. However, the attitude of tourists to the problem of overtourism may vary depending on their ages, because, as in every aspect of life, there are intergenerational differences arising from the political, economic or technological development of the times in which a given generation grew up. The main purpose of the article is to examine the public awareness of the phenomenon of overtourism in the context of intergenerational differences, as well as to determine the impact of tourists on the places visited and the local community. The study was conducted on a sample of 386 respondents representing the X, Y, and Z generations. The study results showed that there is awareness among all generations of respondents about the problem of overtourism, although indifference to this phenomenon was demonstrated by the youngest respondents ( $Z$ generation). The respondents also agreed on individual elements of their own impact on the environment and residents, but with different determinations. The article ends with recommendations on the introduction of various management practices that should be implemented in order to make tourism more responsible and sustainable in the future. It is proposed that a road map should be compiled at the local level for sustainable tourism development.
\end{abstract}

Keywords: sustainable development; overtourism; Generation X; Generation Y; Generation Z

\section{Introduction}

The world's population is constantly growing, as is the number of tourists. The dynamism of tourism development in the world is due to, in particular, the industrial revolution, i.e., it is associated with the development of transport, speed of movement and the increase in wealth of individual countries and their inhabitants. This translates into an increase in the number of people who can afford to travel more frequently. In 2018, international tourist travel amounted to 1.4 billion people, while 710 million tourists come to Europe [1]. Along with the increase in the popularity of tourism, the problem appears with tourist congestion in visited places and the negative impact of tourists on the environment and residents. The tourism economy is one of the main contemporary sources of organized human impact on the landscape. However, this impact is often negative and interferes with the idea of sustainable development. Therefore, there is a tendency to implement the concept of sustainable development in tourism. According to the World Tourism Organization (UNWTO), we call sustainable tourism the kind that fully takes into account its current and future economic, social, and environmental impact, meeting the needs of visitors, industry, the environment, and host communities. 
The basis of this concept is, therefore, to achieve a balance between the needs of tourists, the natural environment, and local communities. While the objectives of tourists, entrepreneurs, local authorities, and residents converge at the initial stages of tourism development in a defined area, conflicts increase with the expansion of tourism. One such conflict is the situation in which the expectations of tourists collide with the expectations of residents dissatisfied with the burdensome intensity of tourist traffic [2]. Hence, the main objective of the World Tourism Organization's 2030 agenda is to increase the level of sustainability knowledge and inspire the sector to take the necessary measures to accelerate the transition towards more sustainable tourism [3], which affects the sustainable development of individual countries. Therefore, it becomes important to explore the problem of excessive tourism (overtourism), because, although this concept increasingly appears in both media $[4,5]$ and scientific discourse [6-8], in many countries this phenomenon is poorly known [9]. In particular, the awareness of tourists themselves as to their negative impact on the environment and residents seems to be poor. For example, when analysing the number of Internet searches for the term "overtourism" on a weekly basis in Poland in the period from November 2018 to October 2019, it can be seen that the maximum noted was only eighty [10]. It is also assumed that low social awareness in this area is probably not the same in all age groups of tourists. In this regard, it seems interesting to deepen scientific research on the phenomenon of overtourism in relation to specific age groups, or rather generations. The observed differences between generations result from the political and economic situation, and technological development in the times when a given generation grew up [11-13]. That is why they are often characterized by different tastes, dress styles, behaviours, musical preferences, approach to work, and even to travel. Moreover, the age-based classification of the population is often used in the segmentation of the tourism market. Determining the characteristics of the target group allows for a better adaptation of the product to the needs and capabilities of the customer-tourist. What is more, there are intergenerational differences in the motives for undertaking tourist trips, preferences stay in tourist destinations or harmfulness of tourists' impact on the environment. Four generations are distinguished in social sciences [11-13]: Baby Boomers, Generation X, Generation Y, and Generation Z, as well as the youngest Generation Alpha (born after 2010).

Therefore, it seems reasonable to conduct a study diagnosing the phenomenon of overtourism in the context of the awareness of different generations. Therefore, the purpose of the article is to assess the awareness of tourists of different generations in the field of the phenomenon of overtourism, and to learn about their knowledge of their personal impact on visited places and the local community.

\section{Literature Review}

\subsection{Sustainable Development and Sustainable Tourism}

Achieving sustainable development goals requires ensuring the coherence of three key elements: economic growth, social inclusion, and environmental protection, which is important for achieving the well-being of individuals and entire societies. In August 2015, 193 UN (United Nations) member states reached a compromise on the final document of the new agenda "Transforming our world: Agenda for Sustainable Development-2030", which contains 17 goals and 169 tasks. Sustainable development requires action on many levels and entails the implementation of regulations in particular areas. Enterprises, thanks to the implementation of more inclusive and sustainable business models, can, among others, increase their business efficiency and risk management [3] (p. 13). On the other hand, the implementation of the Sustainable Development Goals (SDG) into the enterprise's operations can improve the sector's competitiveness [14]. In many countries, tourism is an important sector of the economy, which brings financial benefits for the state, the region, and the local community. In the world, the largest financial revenues from tourism were noted in Europe (USD 570 billion), as well as Asia and the Pacific region (USD 435 billion) in 2018. [1]. In the European Union (EU), the number of overnight stays at tourist accommodation establishments has been steadily increasing since 2009 and reached 3254.3 million in 2017, with the share of overnight stays provided to foreign tourists 
increasing by $49.2 \%$ [2], while 2018 global earnings amounted to 1.7 trillion [1]. More than half of EU residents' overnight stays (55.2\%) were spent in rented accommodation [15]. Therefore, hotels or similar places need qualified staff to provide tourists with accommodation and other tourist services. In 2016, over 13 million people were employed in the tourism industry in EU countries [15]. Consequently, employment in tourism translates into macroeconomic indicators for the region. In the EU, 21 of 30 regions with the highest tourism intensity have an unemployment rate below the national average [16]. The data presented above indicates a number of financial benefits, which are obtained by destinations eagerly visited by tourists.

Analyzing the number of tourists, we can see their steady increase since 2009. In 2018, international tourist arrivals increased by $5 \%$ and reached 1.4 billion people. [1]. Europe was visited by the largest number of tourists (710 million), while the largest increase in the number of tourists was noted in Asia-Pacific and Africa (7\%) [1]. In 2017, more than half (58\%) of the total nights spent by nonresidents in the EU were spent in Spain, the United Kingdom, Italy, and France [15]. In turn, 62\% of EU residents made at least one personal trip in 2017, while Finns did it the most often (91.3\%) [15]. Analysing European statistics, Poland stands out the most, as in 2018 it was visited by 19.6 million tourists [2]. In this country, one can observe a continuous increase in the number of accommodation facilities provided to tourists. In Poland, in the first half of 2019, compared to the first half of 2018, there was a visible increase in the total number of tourists using an accommodation facility by $6.1 \%$, as well as the number of overnight stays by $6.5 \%$ [16]. At the same time, there was an increase noted in the number of foreign tourists by $4.5 \%$ and the number of nights spent by them by $5.1 \%$ [16]. However, the average share of overnight stays provided to foreign tourists in the total number of overnight stays for the EU was $49.2 \%$, while for Poland it was only $19.9 \%$ [2], which was the second-lowest share of tourists among the surveyed countries. This indicates that the interest of tourists in Poland is growing, despite the fact that now there is a low level of foreign tourists' participation. Therefore, it is necessary to explore the problem of overtourism in Poland, because that phenomenon will increase in strength. Analysing the data of tourism intensity, one can observe a large variation in the scope of guest nights spent in tourist accommodation establishments per inhabitant. Among European countries in 2017, the highest rate was recorded in the following countries: Malta (20.8), Croatia (20.7), Cyprus (19.6), and Austria (13.8), while there was an average of 6.1 guest nights throughout the EU [15]. The presented data indicates that the number of tourists is constantly increasing, which causes high tourist traffic on access routes, in public transport, as well as in the places visited. Moreover, estimates indicate that in 2030, 1.8 billion tourists in the world will cross borders [9]. In 2017, 62\% of EU residents made at least one personal trip [15]. Therefore, in order to ensure sustainable development, it is necessary to take action in the field of sustainable tourism.

The 2030 agenda aims to inspire industries to take measures to maintain sustainable development, including in the area of tourism. This is reflected in Goal 8, "Decent Work and Economic Growth"; Goal 12, "Responsible Consumption and Production"; and Goal 17, "Partnerships for the Goals". Moreover, task 8.9 was formulated stating that, by 2030, policies should be developed and implemented to promote sustainable tourism that creates jobs, and promotes local culture and products. In order to measure the degree of implementation of this measure, an indicator has been developed, which is calculated as a percentage of tourism in relation to GDP. The value of this indicator in 2017, both on a global scale and in Poland, was $0.1 \%$, and its value increased compared to the previous year [15].

Unfortunately, with the expansion of tourist traffic, incidents related to its burden on the natural and cultural environments of tourist areas are increasingly observed. To support sustainable tourism development practices, the World Tourism Organization and the United Nations have developed a Development Program. In it, they recommend that donor countries need to pay special attention to the challenges and needs of developing countries, and that tourism decision-makers in developing countries can attract more funding if their tourism activities focus on those areas that are most relevant for donor countries [3]. In order to ensure sustainable development, it is necessary to identify factors affecting the sustainable development of tourism in the context of a given location. Local authorities 
should support entrepreneurs and provide financial support so that they will be able to develop business models that foster inclusive green growth - in particular in those areas where voluntary action is not sufficient to achieve the SDGs [3]. In order to manage tourist traffic and preserve sustainability, a number of different actions are proposed. Actions are proposed to minimize the anthropogenic impact on the environment and to protect the natural environment and culture $[17,18]$. In turn, other recommendations were formulated to ensure the sustainable development of entertainment tourism [19].

It becomes necessary to conduct research in the field of sustainability in tourism, which is emphasized in the literature [20]. In particular, research on tourists' awareness of their impact on sustainable development appears to be important. Sustainable tourism has been described as tourism "that takes full account of the current and future economic, social, and environmental impacts, addressing the needs of the visitors, the industry, the environment, and host communities" [9]. It indicates that attention should be focused on time, type of influence and various stakeholders. The group of stakeholders is diverse, as it includes both residents and visitors, for whom the expected benefits of tourism are different. Tourists expect access to tourist attractions and amenities for them, while residents demand respect for their rights regarding access to urban infrastructure, public services, and improvement of quality of life.

It should be emphasized that stakeholders have different levels of awareness about the economic benefits of sustainability. This is confirmed by the results of research that showed that the perceptions of the sustainability of the stakeholders involved in rural tourism development were very different [20]. Moreover, tourism enterprises often lack awareness of how efforts and investment in sustainable business operations can also significantly boost competitiveness and profitability, while increasing customer and host community satisfaction [3].

The basic prerequisite to undertake research and to formulate the research problem is the significant increase in the number of tourists, noticeable for years, and the continuous growth of the tourism sector (as estimated by the World Tourism Organization (UNWTO)) by $3.3 \%$ annually until 2030 [9] (p. 4). Tourists visit areas of natural and cultural interest, as well as for entertainment. More and more tourists visit residential areas [18], while entertainment attractions are located in many places to encourage tourists to travel and provide them with joy [20]. The increase in the number of visiting tourists, as well as the development of spending time, will have an effect on other sectors of the economy and enterprises. Moreover, adverse climate change, environmental degradation, population growth, and the growing awareness of buyers about their chosen solutions means that a new approach is needed to build a sustainable and disaster-proof future strategy for society and all organizations. Therefore, it is necessary to take actions, in the field of sustainable tourism development. Such actions were taken, for example, by the Global Sustainable Tourism Council (GSTC), whereby it developed criteria/standards for sustainable development in tourism. These criteria are organized into four pillars [19]:

- $\quad$ sustainable management;

- $\quad$ socio-economic effects;

- impact on culture;

- environmental impact (including resource consumption, pollution reduction, and preservation of biodiversity and landscapes).

For this purpose, it is necessary to examine the level of public awareness of its impact on ensuring sustainable development. This becomes important because of the impact that stakeholders have in economic, social, and environmental terms in a given area[21]. The divergent needs of tourists and residents cause a conflict of interest in the area of tourism, in particular in terms of their impact on the economy, society, and the environment. It is emphasized that sustainable tourism and overtourism are an important context that affects the right to travel and the right to live [18]. Certainly, a discussion is needed on how to achieve sustainable development, in particular in the area of growing tourist traffic. 


\subsection{Overtourism}

The notion of overtourism in literature appeared relatively recently, which is why in many languages there is not yet a shaped translation of this concept. However, the presence of this phenomenon is often observed in the media, which reports on the problems of congestion and the negative impact of tourists on the environment, and on inhabitants in popular tourist destinations $[3,4,22,23]$. Although the term has only appeared in scientific publications only since 2017 [24], this does not mean that this problem has not been raised before. In the 1970s, special indicators were developed to determine the optimal size of tourist traffic for various regions: an absorption indicator, a capacity indicator, and a flow indicator [25]. We also see the beginnings of measuring changes in residents' attitudes towards tourists in the work of Doxey [26], who lists four phases: euphoria, apathy, annoyance, and antagonism. However, in 1980, Butler [27], in the concept of the tourism area life cycle (TALC) points out that tourist destinations negatively feel the consequences of their success. Although the term 'overtourism' was not used at that time, previous publications clearly revealed the potentially negative effects of the rapidly growing tourism sector. The TALC concept already contains elements that quantify overtourism, by using the terms 'tourism capacity' and 'absorbency'. Four decades later, the same author tackles the topic of overtourism to its full extent [28].

The World Tourism Organization (UNWTO) defines overtourism as: "the impact of tourism on a destination, or parts thereof, that excessively influences the perceived quality of life of citizens and/or quality of visitors' experiences in a negative way" [3]. In contrast, the EU [24] in its research on overtourism describes this phenomenon as: "the situation, in which the impact of tourism, at certain times and in certain locations, exceeds physical, ecological, social, economic, psychological, and/or political capacity thresholds". The definition of the phenomenon of excessive movement around the world, with the following references to literature, both historical and current research, is discussed extensively by Kruczek [29].

Currently, according to recent studies [30-32], excessive tourism causes, among other issues, alienation of residents, a worsening of the tourist experience by visitors, an overload of infrastructure, damage to the natural environment, and a threat to culture and heritage. Every year, the number of cities in the world, such as Venice, Barcelona, Dubrovnik, Amsterdam, Berlin, Prague, Hong Kong, Rio de Janeiro, Shanghai, Palma de Mallorca, and Lisbon [33]; or in Poland, such as Zakopane and Kraków [34], that struggle with the problem of excessive tourist traffic, increases.

There are three dimensions to the negative impact of overtourism [24] (pp. 87-88): environmental, economic, and social. The consequences of excessive tourism for the natural environment primarily include overpopulation and devastation in places attractive to tourists, including natural, historical, and architectural places, a strong or noticeable contribution to water, land and air pollution, and problems with solid waste removal [24] (pp. 87-88). In places, where the number of tourists increases significantly, there is a greater economic dependence on tourism, including the strong impact of seasonality and degradation of other sectors or types of employment. Beyond the problems concerning the negative impact of overtourism on the environment and the economy of individual cities, the social dimension is also significant. The growing number of tourists causes many burdens and inconveniences for the local community. It is observed that adaptation to tourists occurs first, and then to residents [8]. Therefore, the implementation of stricter regulations for tourists is recommended to ensure inhabitable, tourist-friendly cities [35].

In particular, the young generation can be a big problem for the local community, because their way of spending time disturbs the peace in tourist destinations. Young people are eager for new experiences-for many of them traveling is the goal of life, their passion. The social effects of overtourism are also the worsening of (perceived) security, due to increased crime and violence, problems related to uncivilized behavior, alcohol consumption, prostitution, gambling, and drug trafficking. It also leads to possible misunderstandings or hostility (e.g., social conflicts and protests) [24] (pp. 87-88). In addition, it can also weaken local cultural traditions, moral values, and standards, leading to a loss of community spirit and pride, as well as a loss of the given country's cultural identity. 
Cities recognize the problem of overtourism and are looking for different solutions $[2,4,5,7,8,36]$. There is a lively discussion regarding the rights of tourists and residents [37]. Politicians, city managers, and scientists are wondering how to solve the problem of tourist congestion [38] having a negative impact on the local community and the environment [22].

Various kinds of strategies and countermeasures are adopted. For example, the following can be mentioned [9] (p. 10): promoting the temporary dispersion of visitors, stimulating the creation of new routes and attractions for visitors, communication, and the involvement of local stakeholders and visitors. Solutions are being implemented for the adaptation of tourism practices, increasing the capacity of existing systems, and improving residents' perceptions of tourism, also by means of "smart" technological solutions [8]. It is also worth providing local communities with the opportunity to enjoy tourist attractions and create places that benefit both the residents and visitors.

In turn, EU recommendations [24] (pp. 87-88) contain, among other items, such guidelines as conducting more systematic research on the issue of excessive tourism in rural areas, coasts, and islands, as well as natural and cultural heritage; initiating debates on tourism development; and management of economy sharing platforms, such as Airbnb [39]. Moreover, more attention was paid to the qualitative elements of tourism development (profitability, local employment, fair pay rates) and not just the increase in the number of tourists. An important aspect is also supporting the monitoring of the "moods" of tourists, hosts, and (other) residents to earlier notice psychological and social problems during the excessive development of tourist traffic. Moreover, managers in tourist cities should collect data on the stay duration, expenditure, and/or intention to act, in order to identify profitable markets that are more economically, socially and environmentally resilient [6].

The problem of excessive tourism can also be solved by striving to develop sustainable tourism destinations, in this way balancing the equality of the right to travel with the rights of residents. This requires the involvement and cooperation of a wide range of stakeholders, thanks to which it is possible to implement tourism planning and management measures that will be accepted by everyone. An example is the Paris Agreement on Climate Change, which helped mobilize individuals, industries, governments, and other organizations to cooperate, in order to reduce greenhouse gas emissions [14]. However, to adopt some general principles and assumptions, it is necessary to thoroughly investigate and describe this phenomenon.

\subsection{Travel by Generations}

Assuming that the generation is an identifiable group of people, who share similar birth times and experience of important events at development stages, one can now point to four generations of people indicated in the scientific literature, ([11,13,40], ([41] p.234), ([42] p.307), [43]) those active and physically fit enough to enjoy tourist trips [44]. Namely, they are [43]:

- Baby Boomers (BB)-born in 1945-1964, the so-called generation of the baby boom and economic boom;

- Generation X-born in 1965-1980, growing up during the economic crisis of the 1970s;

- Generation Y (Millennials) - born in 1981-1994, brought up in the era of globalization and universal access to the Internet;

- Generation Z-born after 1995, which uses modern information and communication technology for everything.

The next generation after $Z$ is the Alpha Generation (born after 2010). It is a group of children aged nine years and younger, so they are not considered in the elaborated study.

The Baby Boomers generation nowadays is taking an increasingly active part in recreational activities, such as hiking, diving, surfing, climbing, and traveling to various places around the world. The growing mobility of this generation is associated with their well-established social position, financial possibilities, and having more free time because their adult children have started their own families. The eldest of this generation are already retired and those who are still working need more 
time to relax and relieve stress. The needs and interests of the baby-boom generation are changing because this generation has become healthier and wealthier than in previous years [45]. As the Naidoo research [46] shows, the main motivators in making tourist trips of this generation are taking pleasure and joy from traveling, soothing stress and tension, relaxation, the need for change and novelties, as well as the an appreciation of the attractiveness of the physical environment, and caring for better health.

Generation X are people born in 1965-1977, who are currently 37-49 years old, and who grew up and entered adult life in Poland during the restructuring of the economy. Inflation, increased unemployment and employment instability forced them to accept temporary contracts and accept jobs below their qualifications. The times in which they had to start their careers made them entrepreneurial people, but also exacerbated the atmosphere of uncertainty and fear associated with the possibility of losing their jobs. However, as mature people, they are most often the owners of large enterprises, as well as supervisors and teachers for Generations Y and Z. Similarly, in the United States, Generation $X$ is described as born in bad economic conditions [47], and their attitudes and beliefs were shaped by the first war in Iraq [47], the climate of school shootings, reality shows [48] and HIV epidemics. Family is first for this generation, which is why they plan trips with the family and children to the sea, mountains, or lakes. They also often visit popular cities, where you can find interesting monuments or rich history. When choosing to travel abroad, they usually look for quiet, recreational places, or interesting cultural monuments. Despite the fact that people from this generation were born in analogue times, they fit perfectly into the modern digital world and modern technologies, which is why they willingly use the Internet when planning and booking their tourist trips.

The phenomenon that shaped Generation Y (Millennials) was globalization, which caused the blurring of barriers between countries, internationalization of enterprises, merging cultures, and increasing access to products and services from around the world. Double earnings of parents have become a standard, guaranteeing good conditions for the personal development of their children. Respect for ethics, multiculturalism, awareness of social problems, and the possibility of using information and communication technology are of great importance for this generation. This generation is extremely mobile, willingly travels, moves from one place to another, and the decision to emigrate is ready to be made quickly and not necessarily for economic reasons. The circle of friends of this generation is not limited to people living in one place, but they have friends all over the world. Their main values are independence, ambition, creativity, innovation, and development. Representatives of Generation $Y$ travel more than their predecessors, they visit and explore a greater number of destinations, spend more while traveling and are eager for interesting experiences and information [46,49]. Moreover, as research by Dębski [50] and Xiang, Magnini, Fesenmaier [31] indicate, people from Generation Y show a strong need to use the opportunities generated by the Internet and social media while planning and sharing their experiences during and after the journey. Research by Santos, Veiga, and Aguas [51] shows that Millennials are an increasingly important and larger group in tourism, which is also associated with their great need to travel. Moreover, they highly value travel comfort and follow a variety of adventures, seek unique experiences, and do not just expect passive recreation. Generation $Y$ tourists are increasingly avoiding mass tourism, wanting to be seen as travelers rather than tourists [51]. This is associated with greater independence in planning trips and also with their concerns about the environment [52]. In comparison with Baby Boomers and Generation X, Generation $Y$ is much more active when it comes to planning travel trips or booking accommodation through the Internet (dedicated websites, e.g., booking.com), or using social media (such as TripAdvisor) [53].

Despite that the representatives of Generation $Z$ have many features in common with representatives of Generation Y, there is agreement among researchers [12,44,54] of this generation, that although some features are more visible in them, they are significantly different in many respects. Generation $\mathrm{Z}$ is a generation open to the world and novelties, not only technological but also those related to exploring new places. This is a multitasking generation, where social media is their main form of communication. A characteristic feature of this category is often the preference for virtual relationships, rather than establishing real interpersonal relationships. People from Generation $\mathrm{Z}$ are 
very open to the world and willingly undertake various forms of tourist activity, although they often lack financial resources because they are not yet professionally employed and are dependent on their parents. Therefore, due to financial restrictions, this group dominates domestic recreation, with family or friends. A survey conducted by Expedia Group Media Solutions in 11 different countries in 2017 and 2018 revealed that representatives of Generation Z most often travel to rest (59\%), visit family $(41 \%)$, take part in special events (26\%), or for entertainment purposes (21\%). The analysis of Expedia Group Media Solutions also shows that $84 \%$ of people from Generation Z think that social media plays an important role when planning travel. On social networks, they look for promotions, among other things, as well as getting inspiration to travel by viewing photos and videos published by friends or experts. It is also worth noting that as many as $66 \%$ of the representatives of Generation $\mathrm{Z}$ during trip planning are not committed to a specific destination and are open to inspiration regarding the holiday spot and the place of departure $(74 \%)$.

\section{Materials and Methods}

In order to get the answer to the research questions posed in the article, it was necessary to conduct empirical research among people from different generations, where the division of society into different groups was made on the basis of literature analysis. The main criterion for dividing the respondents was the generation the respondent came from. They were determined based on the respondent's year of birth. The sample was stratified random sampling in Poland. However, the respondents had to have one consistent feature, which was experienced in the field of tourist trips. A pre-test was conducted and some adjustments were made before sending the questionnaire. The invitation to the survey was distributed by 424 emails in October 2019. In order to reach people of different ages (generational layers), who have undertaken tourism activity in recent years, emails with the link have been shared on discussion forums and travel groups on social media.

The research questionnaire contained seven questions, two of which had an extensive structure, including testing the agreement of respondents with the opinions presented on the occurrence of overtourism and their own impact on the tourist area. The choice of questions was deliberate, as they were to indicate selected phenomena that resulted in the occurrence of overtourism in tourist destinations. In several cases, the question was repeated in the opposite context to verify the reliability of the answers given. Thanks to the Likert scale used, it was possible to choose one of five response variants, arranged symmetrically, in terms of positive or negative reference to the issue being addressed. The choice of an intermediate answer meant a neutral attitude to the issue under review, or no opinion on a given topic. The obtained responses were quantified in such a way that a positive attitude towards a particular phenomenon was assessed by a value of 2 or 1 when the positive response was supported only partially. In the case of a negative rating, the grade awarded was -2 , unless it was partially negative, then the grade -1 was allocated. The neutral grade was awarded with a value of 0 . Meanwhile, the average rating of a given response variant higher than zero means a positive attitude of all respondents to the issue. A negative average value indicated a negative attitude of all respondents to a given opinion. This made it possible to compare the responses given by nonparametric statistical tests in individual groups designated by generational identification. The main questions were followed by a record specifying their gender, age, and education, as well as tourist experience, differentiated by the length and frequency of tourist trips.

After the initial selection of collected questionnaires, 396 respondents were qualified for further analysis, which exceeded the minimum random sample size estimated at 386 questionnaires (for the assumed maximum statistical error rate of the sample of $\pm 5 \%$ and the confidence level $p=0.95$ ).

The elaboration of the collected data involved the performance of statistical analysis, of both one-dimensional (in the form of classical or positional descriptive analysis) and two-dimensional (in the form of analysis of the relationships of pairs of tested features) natures, and even in a multidimensional dimension, by means of correspondence analysis [55]. In some cases, the level of significance of differences between the obtained average values was also studied. For comparison of two 
groups of variables with a distribution different than normal, the U (Mann-Whitney) test was used [56]. The significance of differences between structure indicators was verified with the Chi-squared test. When verifying statistical hypotheses, the statistical tests were used, taking into account significance at the level of $\alpha \leq 0.05$. In the interdependence analysis, Pearson's linear correlation coefficients and $\mathrm{t}$-Student significance test for the correlation coefficient were used [57].

Correspondence analysis is a method of multivariate qualitative analysis, using a two-dimensional comparison of many variables by using their taxonomic distances. The results of correspondence analysis are presented in two-dimensional drawings of mutual relations of the qualitative responses obtained.

\section{Results of Research}

The survey involved 386 respondents, among whom 59.8\% were women and $40.2 \%$ men. Taking into account the criterion of division of the respondents according to generations, the survey sample included $58.8 \%$ of people from Generation Z, 21.5\% of people from Generation $Y$ and $19.7 \%$ of people from Generation X. The BB generation also took part in the study. However, it was not possible to obtain sufficient numbers of this group of respondents $(<30)$. This is not a sufficient representation of the respondents on the basis of which it is possible to infer, therefore this generation was omitted in further analyses. Table 1 gives the structure of the respondents. It already covers only three generations. Undoubtedly, this is one of the limitations of the presented study, which is why it will be undertaken in subsequent studies of the authors. Among the respondents, well-educated people predominated-over $60 \%$ of people had at least post-secondary education (first-degree graduates). High school graduates constituted $38.6 \%$ of respondents (Table 1 ).

Table 1. Structure of respondents.

\begin{tabular}{|c|c|c|c|}
\hline Generations & {$[\%]$} & Length of Tourist Trips & {$[\%]$} \\
\hline$x$ & $19.7 \%$ & no rule & $33.6 \%$ \\
\hline Y & $21.5 \%$ & $1-3$ days & $27.0 \%$ \\
\hline \multirow[t]{2}{*}{$\mathrm{Z}$} & $58.8 \%$ & 4-6 days & $26.5 \%$ \\
\hline & & one week > & $12.9 \%$ \\
\hline Level of Education & [\%] & Frequency of Tourist Trips & {$[\%]$} \\
\hline Basic/Junior high & $1.0 \%$ & less than once a year & $15.4 \%$ \\
\hline Secondary & $38.6 \%$ & once a year on average & $28.3 \%$ \\
\hline Higher I & $27.5 \%$ & several times a year & $56.3 \%$ \\
\hline Higher II & $30.8 \%$ & & \\
\hline Postgraduate & $1.0 \%$ & & \\
\hline $\mathrm{PhD}$ & $1.0 \%$ & & \\
\hline $\begin{array}{c}\text { Gender of } \\
\text { Respondents }\end{array}$ & {$[\%]$} & Knowledge about Overtourism & {$[\%]$} \\
\hline Woman & $59.8 \%$ & Yes, I met this phenomenon personally & $67.7 \%$ \\
\hline Man & $40.2 \%$ & I heard about it from the media/friends & $20.7 \%$ \\
\hline & & No, I've never encountered it & $11.1 \%$ \\
\hline
\end{tabular}

Source: based on own study.

The surveyed people showed a very diverse length of tourist trips including at least one night. More than every fourth respondent usually decided on 1-3 days' weekend trips (27.0\%) or trips lasting 4-6 days (26.5\%). In terms of the frequency of trips, the overwhelming majority (56.3\%) go several times a year, and every fourth $(28.3 \%)$ at least once a year. Every third respondent $(33.6 \%)$ undertook trips of varying lengths. 
Respondents were asked about knowledge on overtourism. Nine out of ten respondents (88.4\%) stated that they knew of this phenomenon. However, every fifth respondent $(20.7 \%)$ heard about this from the media or from friends, while $67.7 \%$ of people came across this phenomenon directly.

Analyzing the responses of the respondents in general (without a generational breakdown) to the questions in which the respondents had to agree or disagree with the opinions presented to them, one can indicate the opinions for which a high degree of agreement has been noticed, as well as several of those to which the respondents disagreed. These opinions can be ranked according to the decreasing degree of agreement of the respondents. This is the following order:

- During the trip, I do not litter the environment, I do not make noise, and I turn off electrical devices when leaving the hotel room (average rating is $1.48 \pm 0.78$ );

- I I always behave in a civilized way, no matter where I am (the average rating is $1.48 \pm 0.80$ );

- During the trip, I use natural resources in the same way as in my home (the average rating is $1.08 \pm 1.00$ );

- My presence in a tourist location means only benefits for residents (the average rating is $0.26 \pm 1.00$ );

- I pay for the holiday, so I can use the local amenities however and whenever I want (average rating is $0.06 \pm 1.28$ );

- To be honest, it is not my concern-I want to relax when I feel like it (average rating is $0.04 \pm 1.39$ );

- This is an exaggeration-in my opinion, the negative impact of tourists is exaggerated (the average rating is $-0.30 \pm 1.04$ );

- During the trip, I sometimes use more water for washing and more electricity than at home (the average rating is $-0.51 \pm 1.29$ );

- I believe that during a tourist trip I am free to do more, I am on holiday after all (average score is $-0.61 \pm 1.30$ );

- I do not intend to deal with what the residents think about my presence and behavior (average score is $-0.76 \pm 1.16)$.

According to the adopted methodology for assessing individual issues, the following intergenerational differences can be noticed:

- Indifference to the phenomenon of overtourism was demonstrated by the youngest respondents (Z generation). Their results of agreement with the opinion that overtourism is not their concern are similar and positive, which means that they generally agree with this opinion. Intermediate groups of respondents ( $X$ and $Y$ generations) do not agree with indifference to this phenomenon. Comparative analysis between the generations confirmed that there is a statistically significant difference between the average ratings of the $\mathrm{X}$ and $\mathrm{Z}$ generations $(p<0.001)$ and $\mathrm{Y}$ and $\mathrm{Z}$ $(p=0.020)$.

- In general, all respondents agree that tourist visits are associated with benefits for residents. Generation $\mathrm{Y}$ agrees with this statement much more often than people from other generations, in which there is a greater tendency to an intermediate response (difficult to say/I do not know).

- In the case of opinions that the popularity of the phenomenon of overtourism results from exaggerating its real significance, the responses are unambiguous. All generations negatively refer to this statement, which means that in generations $\mathrm{X}, \mathrm{Y}$, and $\mathrm{Z}$ the problem of overtourism is perceived as serious.

- The distribution of responses on the subject of higher water and electricity consumption during tourist stays is interesting. The respondents from all generations disagree with this opinion, while it is twice as emphatic in Generation $\mathrm{X}$ than in the $\mathrm{Y}$ and $\mathrm{Z}$ generations, which show great similarity in this respect $(p=0.767)$.

- The opinion on whether during the tourist trip the respondents were allowed more than in everyday life did not gain approval. In general, the ratings obtained were negative, and in Generation X, strong opposition to this opinion was more frequently expressed $(-1.14 \pm 1.08)$. 
- A material factor related to the opinion that a tourist has the right to use the destination freely, since they pay for it, did not gain the approval of the $X$ and $Y$ generations, while the people of Generation $\mathrm{Z}$ rather agree with this view $(0.41 \pm 1.17)$.

- For all generations of tourists, the opinion of residents on their behavior in the destination turns out to be important. This is indicated by average ratings in all groups, with higher averages again in generations $\mathrm{X}$ and $\mathrm{Y}$.

- The above result seems to be consistent with what was obtained in the study on the responses of respondents from different generations on their opinions about their manners during the trip. All generations agree that their civilized behavior does not depend on where they are, and therefore is identical in a holiday spot and the home environment.

- In the next question, in order to control the reliability of responding, one of the previously asked questions was repeated (but in the opposite context). It was a question about similar consumption of natural resources at home and during a tourist trip. The answers obtained confirm the reliability of the research tool, because the average scores are very similar to those given when asked about water and electricity consumption. Of course, the results were positive this time, because they were put in a positive context.

- The respondents generally strongly agreed with the statement that they do not litter the environment, do not make noise, and turn off electrical devices while leaving the hotel room. What is noticeable here is the fact that the frequency of confirming this opinion decreases with the increasingly lower age of respondents (Table 2).

Table 2. Results of average agreement assessments of respondents from different generations with the opinions presented.

\begin{tabular}{lccc}
\hline $\begin{array}{l}\text { What do You Think About Your Own Impact on the Inhabitants' Environment } \\
\text { and the Environment in the Visited Tourist Destinations? }\end{array}$ & $\mathbf{X}$ & Generations & $\mathbf{Z}$ \\
\hline & Mean \pm Standard Deviation (Median) \\
\hline & $0.49 \pm 1.44$ & $-0.13 \pm 1.33$ & $0.27 \pm 1.34$ \\
\hline To be honest, it is not my concern -I want to relax when I feel like it & $0.16 \pm 1.09$ & $0.45 \pm 0.86$ & $0.21 \pm 1.01$ \\
My presence in a tourist location means only benefits for residents & $-0.5 \pm 1.11$ & $-0.44 \pm 1.04$ & $-0.24 \pm 0.96$ \\
This is an exaggeration - in my opinion, the negative impact of tourists is exaggerated & $-0.85 \pm 1.21$ & $-0.47 \pm 1.16$ & $-0.47 \pm 1.32$ \\
During the trip, I sometimes use more water for washing and more electricity than at home & $-0.36 \pm 1.33$ \\
I believe that during a tourist trip I am free to do more, I am on holiday after all & $-1.14 \pm 1.08$ & $-0.88 \pm 1.21$ & $-0.36 \pm 1.17$ \\
I pay for rest, so I can use the local amenities whenever I want and when I want & $-0.65 \pm 1.18$ & $-0.36 \pm 1.25$ & $0.41 \pm 1.17$ \\
I do not intend to deal with what the residents think about my presence and behavior & $-1.14 \pm 1.01$ & $-0.96 \pm 1.01$ & $-0.58 \pm 1.21$ \\
I always behave in a civilized way, no matter where I am & $1.58 \pm 0.73$ & $1.49 \pm 0.79$ & $1.45 \pm 0.85$ \\
During the trip, I use natural resources in the same way as in my home & $1.27 \pm 0.99$ & $1.06 \pm 0.94$ & $1.05 \pm 1.02$ \\
During the trip, I do not litter the environment, I do not make noise, and I turn off & $1.58 \pm 0.69$ & $1.52 \pm 0.74$ & $1.43 \pm 0.84$ \\
electrical devices when leaving the hotel room & & & \\
\hline
\end{tabular}

Source: own work.

A comparative analysis in terms of average ratings of individual generations proves many previously observed similarities between generations, but also a lot of differences, determined on the basis of a nonparametric test of the significance of differences between means (Table 3). The most significant differences between individual pairs of generations were observed in the case of $X$ and $Z$ pairs $(p<0.001)$. In many cases, these generations expressed opposite opinions, such as in the case of indifference to their own impact on the tourist area, or regarding the requirements for the destination in which they leave their money. Or they had similar opinions, but with radically different firmness, as in the case of allowing oneself more when on holiday, or indifference to the opinions of residents about their behavior. 
Table 3. The results of the nonparametric test of the significance of differences between average ratings for agreement with opinions in individual generations.

\begin{tabular}{lccc}
\hline & & \multicolumn{2}{c}{$\begin{array}{c}\text { Level of Significance of Differences } \\
\text { between Generations }\end{array}$} \\
\cline { 2 - 4 } & $\mathbf{X Z}$ & $\mathbf{X Y}$ & $\mathbf{Y Z}$ \\
\hline To be honest, it is not my concern - I want to relax when I feel like it & 0.001 & 0.088 & 0.020 \\
My presence in a tourist location means only benefits for residents & 0.854 & 0.093 & 0.043 \\
This is an exaggeration - in my opinion, the negative impact of tourists is exaggerated & 0.034 & 0.685 & 0.076 \\
During the trip, I sometimes use more water for washing and more electricity than at home & 0.027 & 0.026 & 0.767 \\
I believe that during a tourist trip I am free to do more, I am on holiday after all & 0.001 & 0.142 & 0.002 \\
I pay for rest, so I can use the local amenities whenever I want and when I want & 0.001 & 0.147 & 0.001 \\
I do not intend to deal with what the residents think about my presence and behavior & 0.001 & 0.209 & 0.019 \\
I always behave in a civilized way, no matter where I am & 0.221 & 0.371 & 0.839 \\
During the trip, I use natural resources in the same way as in my home & 0.054 & 0.041 & 0.805 \\
During the trip, I do not litter the environment, I do not make noise, and I turn off & 0.218 & 0.557 & 0.553 \\
electrical devices when leaving the hotel room & & & \\
\hline
\end{tabular}

Source: based on own study.

In terms of similarities, the fewest discrepancies can be seen between the $X$ and $Y$ generations-there are just two results indicating significant differences between opinions in these generations. The first relates to higher consumption of water and electricity during a tourist trip than at home $(p=0.026)$, while the second concerns the control question, i.e., the opinion that during a tourist trip they use natural resources in the same way as in their own environment $(p=0.041)$. The generation that disagrees less with the opinion that it consumes more water and electricity, as well as agrees less with using natural resources in the same way, is Generation Y.

The impact of individual generations on the area of tourist destinations and residents is similar, although with a varied impact. Representatives of all generations strongly indicate that their presence has an impact on the economic situation of residents. Other indications are no longer that significant (Table 4).

Table 4. The assessment of respondents' own impact on residents and tourist destinations.

\begin{tabular}{lccc}
\hline I Think that My Presence in A Tourist Destination May Affect: & \multicolumn{3}{c}{ Generations } \\
& $\mathbf{X}$ & $\mathbf{Y}$ & $\mathbf{Z}$ \\
\cline { 2 - 4 } & \multicolumn{1}{c}{ Mean \pm Standard Deviation (Median) } \\
\hline Economic situation of residents (living costs, income) & $1.37 \pm 0.66$ & $1.33 \pm 0.79$ & $1.14 \pm 0.95$ \\
State of relations of residents (family/neighborly/friendly) & $0.6 \pm 0.74$ & $0.51 \pm 0.79$ & $0.41 \pm 0.85$ \\
Communication possibilities (moving, parking) & $-0.18 \pm 1.03$ & $-0.22 \pm 1.02$ & $-0.22 \pm 1.18$ \\
Comfort of recreation for residents in their free time & $-0.07 \pm 1.02$ & $-0.13 \pm 1.01$ & $0.01 \pm 1.13$ \\
Religious practices and access to culture by local people & $0.25 \pm 0.81$ & $0.19 \pm 0.73$ & $0.19 \pm 0.88$ \\
Satisfaction of residents with professional life & $0.92 \pm 0.81$ & $0.76 \pm 0.77$ & $0.88 \pm 0.83$ \\
Residents' access to social infrastructure & $0.49 \pm 0.92$ & $0.44 \pm 0.95$ & $0.46 \pm 1.06$ \\
Sense of security on the streets & $0.42 \pm 0.82$ & $0.27 \pm 0.92$ & $0.25 \pm 1.02$ \\
Sense of pride of residents for belonging to the city & $0.76 \pm 0.76$ & $0.79 \pm 0.77$ & $0.83 \pm 0.90$ \\
Condition of the natural environment in the town & $0.01 \pm 1.06$ & $0.14 \pm 1.05$ & $0.09 \pm 1.12$ \\
\hline
\end{tabular}

Source: own work.

Generation $X$, in addition to economic impact, notices its own impact on the satisfaction of residents with professional life $(0.92 \pm 0.81)$ and residents' sense of pride in belonging to the city $(0.76 \pm 0.76)$. They also perceive their own impact on residents' family, neighborly, and friendly relations $(0.6 \pm 0.74)$. This group of respondents generally did not show clear or even moderate opposition to the indicated elements of influence. If they disagreed with them, they usually described some 
factors as indifferent. Such a situation occurred in the case of their impact on the natural environment $(0.01 \pm 1.06)$, or the comfort and relaxation of residents on days off $(-0.07 \pm 1.02)$.

In the case of people from Generation $Y$, the strongest impact is similarly observed in the case of economic impact on residents $(1.33 \pm 0.79)$. A much lower, but clear impact, is seen in the case of a sense of pride in the resident's belonging to the tourist destination community $(0.76 \pm 0.77)$ and the impact on the satisfaction of residents with professional life $(0.79 \pm 0.77)$. Similarly, in the case of Generation X, likewise Generation Y generally does not expressly disagree with the opinions, but is neutral on the same factors as Generation $X$.

Generation $\mathrm{Z}$ also indicated its own economic impact, i.e., impact on living costs and income $(1.14 \pm 0.95)$. Similarly to all the analyzed generations, in Generation $Z$, there is seen to be an impact on the residents' satisfaction with their professional work $(0.88 \pm 0.83)$ and a sense of pride with belonging to a destination $(0.83 \pm 0.90)$.

Summing up the results from particular generations, it is worth noting that, in general, respondents pointed to the same elements of their own impact, but with a different firmness. Generations X, Y, and $Z$ are very similar in their indications and intensity of impact. In addition, average extreme values (both the highest and the lowest) are seen in Generation Z.

The analysis of correspondence made in relation to the collected data allowed confirmation of several previously presented conclusions. The first of two visualizations (Figure 1) presents a set of variables covering the diversity of respondents by the generations they represent, their gender, level of education, and tourist experience expressed in the length and frequency of tourist trips.

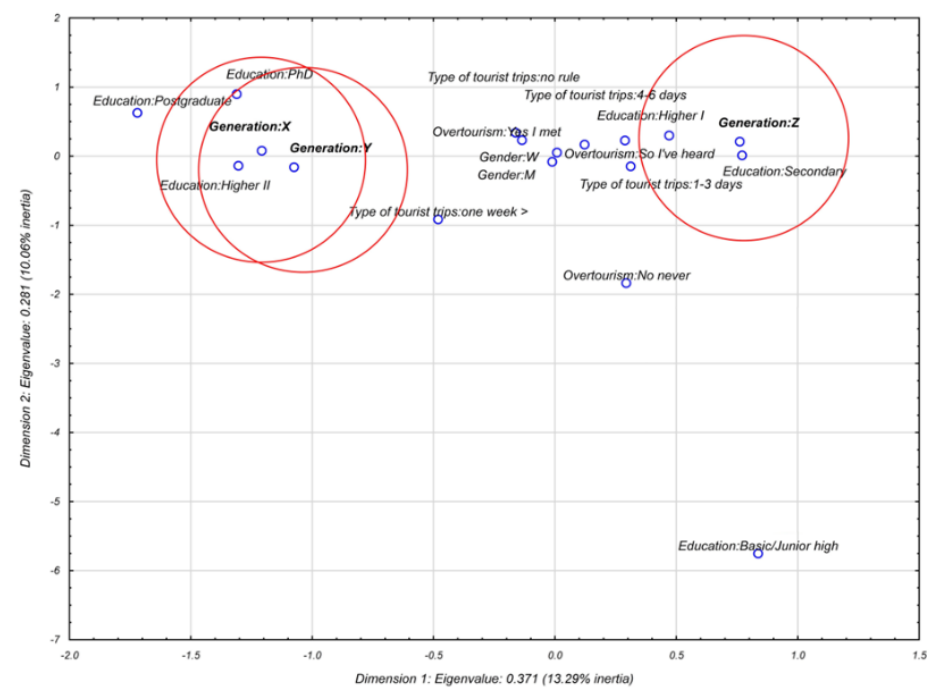

Figure 1. Correspondence analysis results—statement I. Source: own study.

Figure 1 shows a clear separation of the locations of the $\mathrm{Z}$ generations from the generations $\mathrm{X}$ and $\mathrm{Y}$, which are almost identical in their behavior. People from the older generation more often indicated that they had never heard of the phenomenon of overtourism, although the questionnaire explained the definition of this phenomenon and examples of behavior that could express it. Other generations more often showed the recognition of such a phenomenon (in the media or in person). Experience in overtourism did not depend on the gender of the subjects or the length of trips.

The next set, obtained on the basis of correspondence analysis (Figure 2), again proves discrepancies in the responses given by generations. Generations $X, Y$, and $Z$ show, in this respect, both greater tourist activities expressed in the length and frequency of tourist trips undertaken, but also knowledge of overtourism. Generation $Z$ recognizes the phenomenon of overtourism in the media more often than generation $\mathrm{Y}$ and $\mathrm{Z}$. People from Generation $\mathrm{X}$ most often have personal experience in this field. 


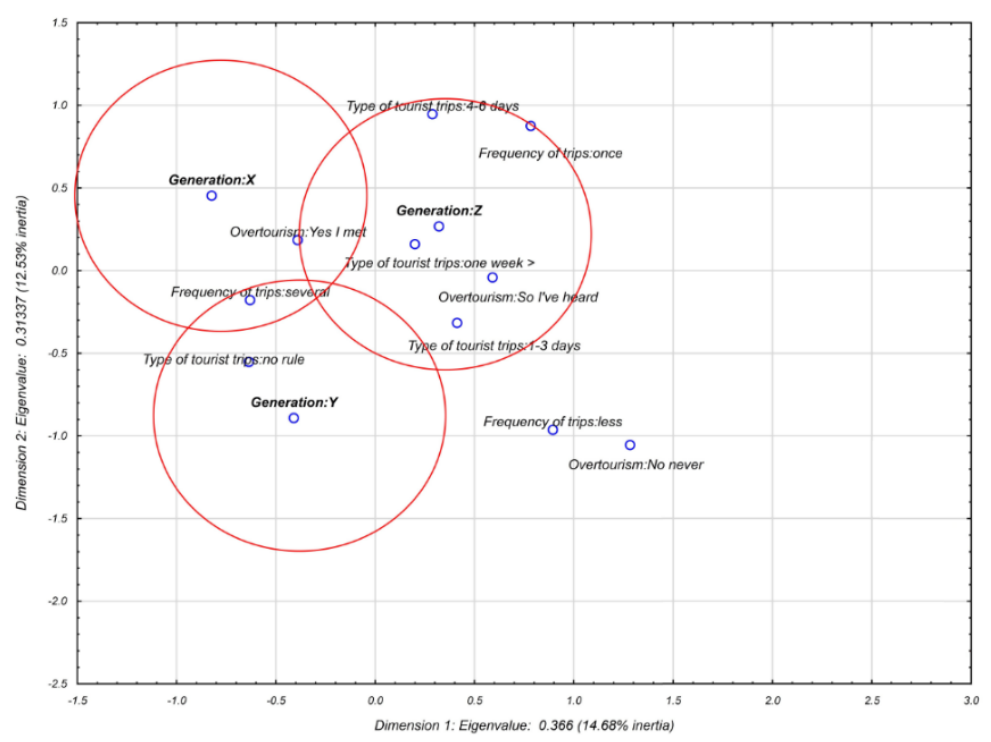

Figure 2. Correspondence analysis results—statement II. Source: own study.

\section{Discussion and Conclusions}

There are significant implications drawn from this study. The study showed that respondents most often take short trips lasting 1-3 days (27\%) and 4-6 days (26.5\%), which confirms the data collected by Eurostat, where [58] short trips dominated among the respondents (50.2\%). The conducted research indicates that Generation $\mathrm{Z}$ is indifferent to the phenomenon of overtourism, based on which it can be concluded that they do not pay attention to the needs of others. This is confirmed by the research of focus groups, on the basis of which it can be stated that the main purpose of the respondents' travel was their own hedonistic experiences. This may indicate selfish behavior towards the residents of a given destination [59]. However, the authors suggested that with natural environments potentially offering a playground for the hedonistic experience, sustainability needs to be fully embedded in the destination management, with the preservation of natural environments becoming the central factor to attracting potential consumers [59]. The approval of the $X$ and $Y$ generations has not gained the opinion that the tourist has the right to use the destination freely, as they pay for it, and representatives of Generation $\mathrm{Z}$ rather agree with this view. Knowledge of these discrepancies in opinions may affect the choice of solutions used in destinations with the aim of solving the problem of overtourism. High demand causes, in many destinations, prices in bars and restaurants to increase, which makes services less available to the local community and some customers. Moreover, bars are closed down, so that hotels and apartments can be built in their place, which means that $18 \%$ of residents consider changing their place of residence [60]. Some of the destinations are considering implementing solutions aimed at attracting high-income tourists. However, this could lead to widening social inequalities. Therefore, it is necessary to develop solutions that ensure equal access to destinations for tourists with different incomes.. In turn, subsequent generations disagreed with this opinion, but it was twice as firm in Generation $X$ than in the case of generations $Y$ and $Z$. Natural resources are limited; therefore, according to UNWTO directives [3] or the GSTC criteria [19], tourists' awareness should be raised and rules for the use of natural resources should be established. This will require a redefinition of tourism, in order to place the rights of local communities above the rights of tourists for holidays and the rights of tourism corporates to make profits [61]. You can use information technology (IT) and social media (SM) solutions, which are being increasingly used by representatives of the young generation [45].

Tourism is a driving force for other sectors of the economy. It is developing very dynamically and brings great financial benefits to various stakeholders. However, apart from the obvious benefits, the tourism industry also has a harmful effect on the natural environment and the local community. As already mentioned, this phenomenon is called overtourism. The negative impact of overtourism can 
be considered in three dimensions [24] (pp. 87-88): environmental, economic, and social. These include overpopulation and devastation in places attractive for tourists, destruction of the natural environment, strong seasonal influence, and an increase in the economic dependence of a given city on tourism, as well as the creation of many burdens and inconveniences for the local community. In particular, the young generation of tourists can be a big problem for the local community, because the way they spend their time disturbs peace in tourist destinations and can cause increased crime or problems related to uncivilized behavior. Overtourism is therefore, a significant barrier to ensure sustainable development.

The results of the conducted research indicate that nine out of ten respondents knew the meaning of the word overtourism and have met it. However, indifference to this phenomenon was indicated by the youngest respondents (Generation Z). Respondents of Generation X and Generation Y showed the least indifference to the problem of overtourism. The respondents also agreed on individual elements of their own impact on the environment and residents, but with different firmness.

Obtaining research results enabled the preparation of managerial and theoretical implications. Recommendations have been prepared for solving the problem of overtourism in economic, environmental and social aspects.

Residents of tourist areas gain economic benefits from tourism; however, the excess of tourist traffic causes conflicts in the social background, therefore, it is necessary to examine the expectations of residents to be able to see psychological, social, economic, or environmental problems. Doxey's [26] or Butler's [27] research on this subject is a good example of this. It is recommended to create a space for discussion, where stakeholders representing different generations would have the opportunity to exchange opinions on sustainable tourism, which would contribute to acquiring new knowledge, increasing their level of awareness in the field of overtourism, and developing various solutions to help solve this problem $[19,32]$. It is necessary to support this process by local authorities in order to take action to counteract the negative impact of tourism on the local community. It is worth having residents participate in it, which will help create optimal solutions. Moreover, it should also be discussed on forums to help engage Generation $\mathrm{Z}$ in discussions, for which social media is important, and appreciate group (crowd-related) problem-solving. This would help to compile strategic documents that would indicate goals and propose solutions in the field of solving the problem of overtourism.

Local authorities should monitor tourist traffic and collect data, including qualitative data, in terms of customer expectations and types of activity, which would allow the creation of road maps for sustainable tourism development. This could include, among other matters, encouraging the extension of stays; expanding the possibilities of spending time; and creating new attractions located in less populated areas, which could be less burdensome for residents. It is worth implementing initiatives that would support local businesses run by residents.

In order to counteract the negative impact of overtourism on the environment, it is proposed to implement smart technologies that would monitor the level of traffic in the city and prevent overcrowding in places attractive to tourists. It is also worth using SM to provide information encouraging tourists to respect local culture and the environment, as well as informing them of the negative effects of not respecting these principles. In order to minimize the negative impact of overtourism on the environment, acceptable levels of tourists' impact on tourist attractions can be defined through a participatory process involving all interested parties. This will make it easier for local communities to reap the benefits, create shared experiences of the city for visitors and residents, and help communicate with residents.

The presented article has its limitations, which is the limited territorial scope of research, as well as the limited number of respondents representing the BB generation. Therefore this generation was excluded from statistical analyses. The small sample of the BB population is most likely due to the way the questionnaire is delivered. The BB generation uses less modern technology, social networking sites, and forums. In order to examine this group of people, it should be considered to use face-to-face interviews based on a questionnaire in different tourist destinations. 
In further research, the authors will examine the generational awareness of overtourism in other countries and make international comparisons. The authors plan to conduct further studies in cooperation with tourist resorts. This will enable to use the recommendations contained in the article. In particular, to increase the awareness level of generation $\mathrm{Z}$, decision-makers should consider using IT technologies and social media, which are natural communication tools for this generation. Another intention of the authors is also to obtain the opinion of the BB generation, therefore the way of distributing the questionnaire will be changed from online to offline.

Author Contributions: A.R.S. prepared the following elements of the article: the methodology, conduct of research, analysis of data, developed research results. B.H. created the review of literature, developed the final contents of the article and proofread. A.K. co-created the review of literature, conclusions and conducted the research.

Funding: This research received funding from the National Science Center in Poland.

Acknowledgments: This paper was published as part of the research project 'A business model for health resort enterprises' No. 2017/25/B/HS4/00301, supervised and financed by the National Science Center in Poland and as part of statutory research No. 13/990/BK_19/0138 at the Silesian University of Technology, Faculty of Organization and Management.

Conflicts of Interest: The authors declare no conflicts of interest. The funders had no role in the design of the study; in the collection, analyses, or interpretation of data; in the writing of the manuscript; or in the decision to publish the results.

\section{References}

1. World Tourism Organization, International Tourism Highlights 2019 Edition. UNWTO, Madrid. Available online: https://www.e-unwto.org/doi/book/10.18111/9789284421152 (accessed on 20 October 2019).

2. Turystyka w UE, GUS. Available online: https://stat.gov.pl/obszary-tematyczne/kultura-turystyka-sport/ turystyka/turystyka-w-unii-europejskiej-dane-za-2017-rok,11,4.html (accessed on 20 October 2019).

3. World Tourism Organization and United Nations Development Programme Tourism and the Sustainable Development Goals-Journey to 2030, Highlights, UNWTO, 2017, Madrid. Available online: https://www.e-unwto.org/doi/pdf/10.18111/9789284419401 (accessed on 20 October 2019).

4. Dickinson, G. A timeline of overtourism: Key moments in global battle between locals and travelers, The Telegraph, 21 August 2019. Available online: https://www.telegraph.co.uk/travel/news/timeline-actionagainst-overtourism/ (accessed on 10 October 2019).

5. Portal Samorządowy. Available online: https://www.portalsamorzadowy.pl/wydarzenia-lokalne/miasta-niepotrzebuja-turystow-szaranczy, 133542.html (accessed on 20 October 2019).

6. Oklevik, O.; Gössling, S.; Hall, C.M.; Kristian, J. Overtourism, optimisation, and destination performance indicators: A case study of activities in Fjord Norway. J. Sustain. Tour. 2019. [CrossRef]

7. Panayiotopoulos, A.; Pisano, C. Overtourism Dystopias and Socialist Utopias: Towards an Urban Armature for Dubrovnik. Tour. Plan. Dev. 2019, 16, 393-410. [CrossRef]

8. Pechlaner, H.; Innerhofer, E.; Erschbamer, G. (Eds.) Overtourism: Tourism Management and Solutions; Series: Contemporary Geographies of Leisure, Tourism and Mobility; Routledge: Abingdon, UK, 2019.

9. 'Overtourism'?-Understanding and Managing Urban Tourism Growth beyond Perceptions | World Tourism Organization. Available online: www.e-unwto.org (accessed on 25 October 2019).

10. Google Website. 2019. Available online: https://trends.google.pl/trends/explore?q=Overtourism (accessed on 30 October 2019).

11. Dolot, A. The Characteristics of Generation, Z; E-mentor, Warsaw School of Economics: Warszawa, Poland, 2018.

12. Grenčíková, A.; Vojtovič, S. Relationship of generations X, Y, Z with new communication technology. Probl. Perspect. Manag. 2017, 15, 558-564. [CrossRef]

13. Hysa, A. Zarządzanie różnorodnościa pokoleniową. Zeszyty naukowe Politechniki Ślaskiej 2016, 97, $385-398$.

14. Erickson, L.; Robinson, J.; Cutsor, J.; Brase, G. Sustainable Development. In Solar Powered Infrastructure for Electric Vehicles: A Sustainable Development; Erickson, L., Robinson, J., Brase, G., Cutsor, J., Eds.; Taylor and Francis Group: Abingdon, UK, 2016.

15. Eurostat Statistic. Available online: https://ec.europa.eu/eurostat/statistics-explained/index.php?title= Tourism_industries_-_employment]Source:Eurostat (accessed on 20 October 2019). 
16. GUS. 2019. Available online: https://stat.gov.pl/obszary-tematyczne/kultura-turystyka-sport/turystyka/ baza-noclegowa-wedlug-stanu-w-dniu-31-lipca-2019-r-i-jej-wykorzystanie-w-pierwszym-polroczu2019-roku, 4,16.html (accessed on 20 October 2019).

17. Kuznetsov Viktor, S. An integrated approach to tourism development in protected natural areas. Arct. North. 2016. [CrossRef]

18. Luo, J.M.; Lam, C.F.; Haobin Ye, B. Barriers for the Sustainable Development of Entertainment Tourism in Macau. Sustainability 2019, 11, 2145. [CrossRef]

19. Global Sustainable Tourism Council. GSTC Criteria for hotels. GSTC Criteria for tour operators. GSTC Criteria for destinations. Available online: http://www.gstcouncil.org/gstc-criteria/ (accessed on 14 August 2019).

20. Perkumiene, D.; Pranskuniene, R. Overtourism: Between the Right to Travel and Residents' Rights. Sustainability 2019, 11, 2138. [CrossRef]

21. Hatipoglu, B.; Alvarez, M.D.; Ertuna, B. Barriers to stakeholder involvement in the planning of sustainable tourism: The case of the Thrace region in Turkey. J. Clean. Prod. 2016, 111, 306-317. [CrossRef]

22. Wu, L. How Cities Around The World Are Fighting Overtourism. 2019. Available online: ttps://www.forbes. com/sites/lesliewu/2019/05/26/how-cities-around-the-world-are-fighting-overtourism/\#20f554db212a (accessed on 20 October 2019).

23. McKinsey \& Company, \& World Travel \& Tourism Council. Coping with success: Managing overcrowding in tourism destination. 2017. Available online: https://www.wttc.org/-/media/files/reports/policy-research/ copingwith-success---managing-overcrowding-in-tourism-destinations-2017.pdf (accessed on 20 October 2019).

24. Peeters, P.; Gössling, S.; Klijs, J.; Milano, C.; Novelli, M.; Dijkmans, C.H.S.; Eijgelaar, E.; Hartman, S. Research for TRAN Committee-Overtourism: Impact and Possible Policy Responses; Policy Department for Structural and Cohesion Policies Directorate-General for Internal Policies: Brussels, Belgium, 2018.

25. Kruczek, Z. Ways to Counteract the Negative Effects of Overtourism at Tourist Attractions and Destinations. In Annales-Universitatis Mariae Curie-Sklodowska, Sectio B, VOL. LXXIV; University School of Physical Education: Kraków, Poland, 2019; pp. 45-57.

26. Doxey, G.V. A causation theory of visitor/resident irritants: Methodology and research inferences. In Proceedings of the Travel Research Association 6th Annual Conference, San Diego, CA, USA, 8-11 September 1975; pp. 195-198.

27. Butler, R.W. The concept of tourism area cycle of evolution: Implications for management of resources. Can. Geogr. 1980, 24, 5-12. [CrossRef]

28. Dodds, R.; Butler, R.W. Overtourism. Issues, Realitis and Solutions. In De Gruyter Studies in Tourism 1; Walter de Gruyter: Berlin, Germany, 2019; pp. 1-22.

29. Kruczek, Z. “Overtourism"-around the definition, Encyclopedia, 2019, v1. Available online: https:// encyclopedia.pub/163 (accessed on 20 October 2019).

30. Coping with success managing overcrowding in tourism destinations, 2017, McKinsey \& Company \& World Travel \& Tourism Council. Available online: https://www.wttc.org/-/media/files/reports/policy-research/copingwith-success---managing-overcrowding-in-tourism-destinations-2017.pdf (accessed on 20 October 2019).

31. Xiang, Z.; Magnini, V.P.; Fesenmaier, D.R. Information Technology and Consumer Behaviour in Travel and Tourism: Insights from Travel Planning Using the Internet. J. Retail. Consum. Serv. 2015, 22, $244-249$. [CrossRef]

32. Expedia Group Media Solutions survey, "Multi-generational travel trends. Travel habits and behaviours of Generation Z, Millennials, Generation X, and Baby Boomers". Available online: https://info.advertising. expedia.com/british-travel-and-tourism-trends-research (accessed on 10 October 2019).

33. Globetrender Website. Available online: https://globetrender.com/2019/05/11/overtourism-crisis/ (accessed on 10 October 2019).

34. Zmyślony, P.; Kowalczyk-Anioł, J. Urban tourism hypertrophy: who should deal with it? The case of Krakow (Poland). Int. J. Tour. Cities 2019. [CrossRef]

35. González, A.T. Venice: the problem of overtourism and the impact of cruises. Investig. Reg.-J. Reg. Res. 2018, 42, 35-51.

36. Benner, M. From overtourism to sustainability: A research agenda for qualitative tourism development in the Adriatic. German J. Econ. Geogr. 2019, 92213, 1-18.

37. Butler, R.W.; Szromek, A.R. Incorporating the Value Proposition for Society with Business Models of Health Tourism Enterprises. Sustainability 2019, 11, 6711. [CrossRef] 
38. World Tourism Organization. Making Tourism More Sustainable-A Guide for Policy Makers; UNEP and UNWTO: Madrid, Spain, 2005; pp. 11-12. Available online: http://www.unep.fr/shared/publications/pdf/ DTIx0592xPA-TourismPolicyEN.pdf (accessed on 10 October 2019).

39. Milano, C.; Novelli, M.; Joseph, M. Overtourism and Tourismphobia: A Journey through Four Decades of Tourism Development, Planning and Local Concerns. Tour. Plan. Dev. 2019, 14, 353-357. [CrossRef]

40. Smola, K.W.; Sutton, C.D. Generational differences: Revisiting generational work values for the new millennium. J. Organ. Behav. 2002, 23, 363-382. [CrossRef]

41. Smolbik-Jęczmień, A. Rozwój kariery zawodowej przedstawicieli pokolenia X i Y w warunkach gospodarki opartej na wiedzy. Nierówności Społeczne a Wzrost Gospodarczy 2013, 36, 228-238.

42. Mazur-Wierzbicka, E. Kompetencje pokolenia Y—wybrane aspekty, Studia i prace Wydziału Nauk Ekonomicznych i Zarzadzania Nr 39, t. 3; Wydawnictwo Naukowe Uniwersytetu Szczecińskiego: Szczecin, Poland, 2015; pp. 307-320.

43. McCrindle, M. The ABC of XYZ: Understanding the Global Generations Kindle Edition; McCrindle Research Pty Ltd.: Sydney NSW, Australia, 2014.

44. Lyons, S.T.; Schweitzer, L.; Ng Eddy, S.W. How have careers changed? An investigation of changing career patterns across four generations. J. Manag. Psychol. 2015, 30, 8-22. [CrossRef]

45. Ruth, N.; Bolton, A.; Parasuraman, A.; Hoefnagels, A.; Migchels, N.; Kabadayi, S.; Gruber, T.; Loureiro, Y.K.; Solnet, D. Understanding Generation Y and Their Use of Social Media: A Review and Research Agenda. J. Serv. Manag. 2013, 24, 245-267.

46. Naidooa, P.; Ramseook-Munhurrunb, P.; Seebaluckc, N.V.; Janvierd Procedia, S. Investigating the Motivation of Baby Boomers for Adventure Tourism. Soc. Behav. Sci. 2015, 175, 244-251. [CrossRef]

47. Zabel, K.L.; Benjamin, B.J.; Biermeier-Hanson, B.B.J.; Baltes Early, B.J.; Shepard, A. Generational Differences in Work Ethic: Fact or Fiction? J. Bus. Psychol. Sci. Bus. Media 2016. [CrossRef]

48. Kupperschmidt, B.R. Multigeneration employees: Strategies for effective management. Health Care Manag. 2000, 19, 65-76. [CrossRef]

49. Vukic, M.; Kuzmanovic, M.; Kostnic Stankovic, M. Understanding the Heterogeneity of Generation Y's Preferences for Travelling: A Conjoint Analysis Approach. Int. J. Tour. Res. 2015, 17, 482-491. [CrossRef]

50. Dębski, M.; Krawczyk, A.; Dworak, D. Wzory zachowań turystycznych przedstawicieli Pokolenia Y. In Studia i Prace Kolegium Zarządzania Finansów, Zeszyt Naukowy 172; Uniwersytet Warszawski: Warsaw, Poland, 2019; pp. 9-27.

51. Santos, M.C.; Veiga, C.; Aguas, P. Tourism Services: Facing the Challenge of new Tourist Profiles. Worldw. Hosp. Tour. Themes 2016, 8, 654-669. [CrossRef]

52. Leask, A.; Fyall, A.; Byron, P. Generation Y: An Agenda for Future Visitor Attraction Research. Int. J. Tour. Res. 2014, 16, 462-471. [CrossRef]

53. Sun, S.; Nang Fong, L.H.; Law, R.; Luk, C. An Investigation of Gen-Y's Online Hotel Information Search: The Case of Hong Kong. Asia Pac. J. Tour. Res. 2016, 21, 443-456. [CrossRef]

54. Huang, Y.-C.; Petrick James, F. Generation Y's Travel Behaviours: a comparison with Baby Boomers and Generation X. In Tourism and Generation Y; Beckendorff, P., Moscardo, G., Pendergast, D., Eds.; CABI: Wallingford, UK, 2010; pp. 27-37.

55. Greenacre, M.; Hastie, T. The Geometric Interpretation of Correspondence Analysis. J. Am. Stat. Assoc. 1987, 82, 437-447. [CrossRef]

56. Stanisz, A. (Ed.) Biostatystyka; Wyd. Uniwersytetu Jagiellońskiego: Kraków, Poland, 2005; pp. $109-409$.

57. Kendall, M.G. Multivariete Analysis; Charles Griffin: London, UK, 1975; pp. 3-198.

58. Eurostat. 2019. Available online: https://ec.europa.eu/eurostat/statistics-explained/index.php/Tourism statistics\#Tourism_expenditure:_highest_spending_by_German_residents (accessed on 15 October 2019).

59. Hanna, P.; Font, X.; Scarles, C.; Weeden, C. Harrison Ch: Tourist destination marketing: From sustainability myopia to memorableexperiences. J. Destin. Mark. Manag. 2018, 9, 36-43. [CrossRef] 
60. Smith, M.K.; Sziva, I.P.; Olt, G. Overtourism and Resident Resistance in Budapest. Tour. Plan. Dev. 2019, 16, 376-392. [CrossRef]

61. Higgins-Desbiolles, F.; Carnicelli, S.; Krolikowski, C.; Wijesinghe, G.; Boluk, K. Degrowing tourism: rethinking tourism. J. Sustain. 2019. [CrossRef] 